\title{
Incidence of malignant tumours in patients with a non-functioning pituitary adenoma
}

\author{
Daniel S Olsson', Casper Hammarstrand1, Ing-Liss Bryngelsson², Anna G Nilsson', \\ Eva Andersson33, Gudmundur Johannsson 1,* and Oskar Ragnarsson 1,*
}

\author{
1Department of Endocrinology, Institute of Medicine, Sahlgrenska Academy, University of Gothenburg \\ and Sahlgrenska University Hospital, Gothenburg, Sweden \\ 2Department of Occupational and Environmental Medicine, Örebro University Hospital, Örebro, Sweden \\ ${ }^{3}$ Department of Occupational and Environmental Medicine, Institute of Medicine, Sahlgrenska \\ Academy, University of Gothenburg and Sahlgrenska University Hospital, Gothenburg, Sweden \\ *(G Johannsson and O Ragnarsson contributed equally to this work)
}

Correspondence should be addressed to D S Olsson

Email

daniel.olsson@gu.se

\begin{abstract}
Whether patients with non-functioning pituitary adenoma (NFPA) are at increased risk of developing malignant tumours has been sparsely studied and is a matter of debate. In this study, we have investigated the incidence of malignant tumours in a large and unselected group of patients with NFPA. The study was nationwide and included all patients diagnosed with NFPA between 1987 and $2011(n=2795)$ in Sweden, identified in the National Patient Register. Malignant tumours, occurring after the NFPA diagnosis, were identified in the Swedish Cancer Register between 1987 and 2014. Standardised incidence ratios (SIRs) for malignant tumours with $95 \%$ confidence intervals $(\mathrm{Cl})$ were calculated using the Swedish population as reference. In total, 448 malignant tumours were detected in 386 patients with NFPA, as compared to 368 expected malignancies in the general population (SIR 1.22 (95\% Cl 1.11-1.33)). The incidence of neoplasms of the brain was increased (SIR 5.83 (95\% Cl 4.03-8.14)). When analysing the total incidence of malignancies excluding neoplasms of the brain, the overall SIR was still increased (SIR $1.14(95 \% \mathrm{Cl} 1.03-1.26))$. The incidence of malignant neoplasm of skin other than malignant melanoma (SIR 1.99 (95\% Cl 1.55-2.52)) and malignant melanoma (SIR $1.62(95 \% \mathrm{Cl} 1.04-2.38)$ ) were increased, whereas the incidence of breast cancer (SIR $0.65(95 \% \mathrm{Cl} 0.42-0.97)$ ) was decreased. The incidence of other types of malignancies did not differ significantly from the expected incidence in the general population. In conclusion, patients with NFPA have an increased overall risk of developing malignancies. To what extent these findings are due to more frequent medical surveillance, genetic predisposition or endocrine changes, remains unknown.
\end{abstract}

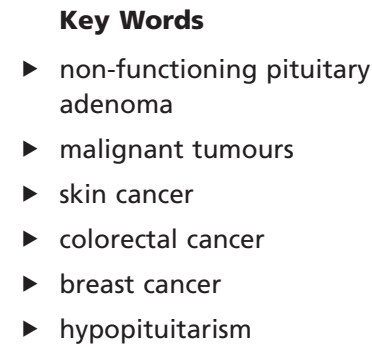

Endocrine-Related Cancer (2017) 24, 227-235 


\section{Introduction}

Patients with hypopituitarism of various aetiologies have increased vascular morbidity and mortality (Rosen \& Bengtsson 1990, Nilsson et al. 2000, Tomlinson et al. 2001, Sherlock et al. 2010, Pappachan et al. 2015). Also, patients with non-functioning pituitary adenoma (NFPA), both with and without hypopituitarism, have excess morbidity due to myocardial infarction, cerebral infarction, type 2 diabetes mellitus, septicaemia and fractures (Olsson et al. 2016). Furthermore, mortality is increased in patients with NFPA, mainly due to cerebrovascular disease and infections (Olsson et al. 2015b).

Previous studies have shown an increased risk of secondary brain tumours in patients with pituitary adenomas, especially patients who have received pituitary radiation therapy (Brada et al. 1992, Tsang et al. 1993, Minniti et al. 2005, Erridge et al. 2009, Norberg et al. 2010). Whether patients with pituitary adenoma are at increased risk of developing other forms of malignant tumours has been sparsely studied and remains a matter of debate. A few studies have shown an increased overall rate of malignant tumours (Bliss et al. 1994, Popovic et al. 1998), others normal rate (Erfurth et al. 2001a, Minniti et al. 2005, Norberg et al. 2008, Sattler et al. 2012) or even reduced rate (Child et al. 2015). Most of these studies have major limitations, including small number of patients, short follow-up time, various types of selections and/or heterogeneous study populations in terms of aetiology and treatment.

The primary aim of this nationwide study was to investigate the incidence of malignant tumours in a large and unselected group of patients with NFPA. Our secondary aims were to study the influence of gender, pituitary tumour treatment and hypopituitarism on the incidence of malignancies.

\section{Materials and methods}

\section{Study design}

The Swedish National Patient Register (Patient Register) was used to identify patients with a diagnosis of NFPA in Sweden. The Patient Register reached a total national coverage in 1987 and contains information from every patient visit within the national hospital system. Malignant tumours were identified in the Swedish Cancer Register (Cancer Register), which was established in 1958. It is mandatory for all health care providers to report newly detected malignant tumours, including morphological and laboratory data. Via the Swedish personal identification number, which is unique for every person in Sweden, an individual patient can be followed throughout life in all the National Health registers. The National Board of Health and Welfare secures high quality for the Patient Register and the Cancer Register (Barlow et al. 2009, Ludvigsson et al. 2011).

Patients with an NFPA diagnosis were identified using a combination of identification criteria to ensure a high quality in the selection of the patients. The identification process has previously been described in detail in two studies on mortality and morbidity in the Swedish national cohort of NFPA patients (Olsson et al. 2015b, 2016). Briefly, eligible patients were diagnosed with NFPA (International Classification of Diseases, 10th revision (ICD-10) code D35.2) either at an internal medicine, endocrine, neurological or at a neurosurgical care unit. This inclusion method of combined criteria for identification (both diagnostic codes and department codes) has previously been shown to result in a high sensitivity and specificity in studies of patients with pituitary diseases in epidemiological research in the Nordic countries (Nielsen et al. 2011, Olsson et al. 2015a). An internal validation of the identification process was performed for the studied cohort, which resulted in a positive predictive value of $91 \%$ for the NFPA diagnosis (Olsson et al. 2015b, 2016). Other non-functioning pituitary tumours, mostly cystic pituitary tumours, were found in $4 \%$ of the patients. The result of the internal validation has previously been described in detail (Olsson et al. 2015b, 2016).

Patients with NFPA were identified in the Patient Register from January 1, 1997 (when ICD-10 classification was implemented in Sweden) to December 31, 2011. In addition, the date of their first NFPA diagnosis was recorded from the Patient Register, between January 1, 1987 and December 31, 2011 (including both ICD-9 and ICD-10 classification). The time at risk for the patients with NFPA started on the date of diagnosis (date of the first registered NFPA diagnosis). The follow-up period, in which patients were studied regarding the incidence of malignant tumours, ended on the date of death or at the end of the study (December 31, 2014). All tumours defined as malignant in the Cancer Register were collected, including all neoplasms in the brain. Date of birth, gender, diagnosis of hypopituitarism and diabetes insipidus (DI) as well as pituitary tumour treatments were gathered from the Patient Registry. The degree of hypopituitarism and its management were not available

Published by Bioscientifica Ltd 
in the registry. In the analyses of the potential effect of different tumour treatments, the time at risk started on the date of the tumour treatment. The reference data on the incidence of malignant tumours in the general population were gathered and analysed in the same manner as for the patients.

\section{Ethics}

The study was approved by the Regional Ethics Review Board in Gothenburg, Sweden, and by the National Board of Health and Welfare, Sweden.

\section{Statistical analysis}

Person-years at risk were calculated from study inclusion to death or end of study and stratified according to gender, 5-year age groups and 1-year calendar periods. The expected number of cases for each stratum was calculated using the general Swedish population as reference. The observed number of malignant tumours among subjects with NFPA was compared with that expected using standardised incidence ratios (SIRs). Ninety-five percent CIs were calculated assuming a Poisson distribution of the observed numbers. Subgroup analyses for gender, hormonal deficiencies and tumour treatments were performed. If less than five events were observed, no estimate was made for SIR. SIRs for nonoverlapping subgroups were compared to each other, and $95 \%$ CI of the ratio of SIRs was calculated. No patients in the validated subgroup, originating from the Sahlgrenska University Hospital's uptake area was lost to follow-up, e.g. due to emigration. The software IBM SPSS (version 21; SPSS Institute) and STATA SE (version 12.1; Stata Corp) were used to perform the analyses in the study.

\section{Results}

\section{Background characteristics}

The analysis included data from 2795 Swedish patients (1502 men and 1293 women) diagnosed with NFPA between 1987 and 2011 (Table 1). The mean age \pm S.D. (range) at diagnosis was $58.4 \pm 16.6(1-97)$ years. The median (range) patient-years at risk was 8.6 (0-28), resulting in a total of 26,664 patient-years at risk. Of 2795 patients, 1500 (54\%) had been treated with pituitary surgery and 134 (5\%) with radiotherapy. The median years at risk after radiation therapy was 4.9 years resulting in 761 patient-years at risk.

\section{Overall incidence of malignant tumours}

In total, 448 malignant tumours were detected in 386 patients with NFPA (Table 2), as compared to 368 expected malignancies in the general population (SIR 1.22 (95\% CI 1.11-1.33)) (Table 3). When analysing men and women separately, only men had a statistically significant increased overall incidence of malignancy. Incidence of malignant tumours between men and women was, however, not significantly different $(95 \%$ CI of the ratio of SIRs 0.92-1.38; $P$ value 0.27 ). The incidence of malignant tumours did not significantly differ between patients who had received radiotherapy or not $(95 \%$ CI of the ratio of SIRs $0.84-2.35, P$ value 0.19 ) or between patients with and without hypopituitarism (95\% CI of the ratio of SIRs $0.78-1.16, P$ value 0.62 ).

The median (interquartile range) time from diagnosis of NFPA until the diagnosis of a malignancy was 5.4 (7.6) years (Fig. 1). Twenty-nine cases of malignancy were diagnosed within three months after the date of the NFPA diagnosis. After exclusion of these cases, men with NFPA still had increased overall incidence of malignant tumours

Table 1 Characteristics of the study cohort of patients with non-functioning pituitary adenoma.

Gender, $n(\%)$
Men
Women
Age at diagnosis, mean \pm s.D.
Men, mean \pm s.D.
Women, mean \pm S.D.
Diagnosed with hypopituitarism, $n(\%)$
Diagnosed with diabetes insipidus, $n(\%)$
Median patient-years at risk per patient, year (range)
Patient-years at risk in the study
Treatment with surgery, $n(\%)$
Treatment with radiotherapy, $n(\%)$

๑ 2017 Society for Endocrinology Printed in Great Britain

\begin{tabular}{c} 
Total $(n=2795)$ \\
\hline $1502(54)$ \\
$1293(46)$ \\
$58.4 \pm 16.6$ \\
$60.2 \pm 15.5$ \\
$56.2 \pm 17.5$ \\
$1523(55)$ \\
$151(5.4)$ \\
$8.6(0-28)$ \\
26,664 \\
$1500(54)$ \\
$134(5)$
\end{tabular}

Published by Bioscientifica Ltd 
Table 2 Frequency of malignancies in 2795 patients with non-functioning pituitary adenoma.

Type of neoplasm
Malignant neoplasm of prostate (C61)
Other malignant neoplasms of skin (C44)
Malignant neoplasm of lymphoid, haematopoietic and related tissue (C81-C96)
Malignant neoplasm of colon (C18)
Malignant melanoma of skin (C43)
Malignant neoplasm of breast (C50)
Neoplasm of meninges (C70)
Malignant neoplasm of bronchus and lung (C34)
Malignant neoplasm of bladder (C67)
Malignant neoplasm of other endocrine glands and related structures (C75)
Neoplasm of brain (C71)
Glioblastoma (Astrocytoma grade IV)
Oligodendroglioma
Astrocytoma grade III
Malignant neoplasm of brain UNS
Malignant neoplasm of rectum and of anus and anal canal (C20, C21)
Malignant neoplasm, primary site unspecified (C76, C78-C80)
Malignant neoplasm of pancreas (C25)
Malignant neoplasm of corpus uteri (C54)
Malignant neoplasm of stomach (C16)
Malignant neoplasm of liver and intrahepatic bile ducts (C22)
Malignant neoplasm of larynx (C32)
Malignant neoplasm of ovary (C56)
Malignant neoplasm of small intestine (C17)
Malignant neoplasm of kidney, except renal pelvis (C64)
Neoplasm of spinal cord, cranial nerves and other parts of central nervous system (C72)
Neurinoma
Meningioma

\begin{tabular}{c}
\hline Gender $(\mathrm{M} / \mathrm{W})$ \\
\hline $91 / 0$ \\
$53 / 17$ \\
$21 / 9$ \\
$15 / 11$ \\
$17 / 8$ \\
$1 / 23$ \\
$6 / 15$ \\
$15 / 5$ \\
$14 / 6$ \\
$7 / 5$ \\
$4 / 6$ \\
$3 / 3$ \\
$0 / 2$ \\
$1 / 0$ \\
$0 / 1$ \\
$6 / 3$ \\
$6 / 3$ \\
$6 / 2$ \\
$0 / 8$ \\
$4 / 1$ \\
$2 / 3$ \\
$5 / 0$ \\
$0 / 5$ \\
$3 / 1$ \\
$4 / 0$ \\
$1 / 3$ \\
$1 / 2$ \\
$0 / 1$ \\
\\
4 \\
\hline
\end{tabular}

\begin{tabular}{c}
\hline Frequency \\
\hline 91 \\
70 \\
30 \\
26 \\
25 \\
24 \\
21 \\
20 \\
20 \\
12 \\
10 \\
6 \\
2 \\
1 \\
1 \\
9 \\
9 \\
8 \\
8 \\
5 \\
5 \\
5 \\
5 \\
4 \\
4 \\
4 \\
3 \\
1
\end{tabular}

All different types of neoplasms with at least 4 cases were declared. In parenthesis, the ICD-10 classification is provided.

(SIR 1.22 (95\% CI 1.08-1.37)) (Table 3). When comparing men against women, no significant difference was found (95\% CI of the ratio of SIRs $0.94-1.42 ; P$ value 0.18 ).

\section{Incidence of specific types of malignant tumours}

The incidence of malignant neoplasm of skin (other than malignant melanoma) was increased (SIR 1.99 (95\% CI 1.55-2.52)) (Table 4). Analyses of subgroups showed that patients with hypopituitarism had a higher incidence than patients without hypopituitarism (SIR 2.38 (95\% 1.78-3.11) vs SIR 1.33 (95\% 0.77-2.12); $P$ value 0.048 ). The incidence of malignant melanoma (SIR 1.62 (95\% CI 1.04-2.38)) (Table 4) was also increased without showing an influence of hypopituitarism (data not shown).

The incidence of breast cancer was decreased in women (SIR 0.59 (95\% CI 0.37-0.89)) with the lowest ratio in women with hypopituitarism (SIR 0.53 (95\% CI 0.27-0.95)) (Table 4). The incidence of prostate cancer was not significantly increased in men.

The incidence of neoplasms of the brain in the cohort was increased (SIR 5.83 (95\% CI 4.03-8.14)), both in men
(SIR 3.75 (95\% CI 1.94-6.55)) and in women (SIR 8.35 (95\% CI 5.23-12.6)) (Table 4). None of the 134 patients who received radiation therapy developed a neoplasm of the brain. The most common brain neoplasms were meningioma $(n=21)$ and astrocytoma grade III and IV $(n=7)$. After excluding neoplasm of the brain, men still had an increased overall incidence of malignant tumours compared to the general population (SIR 1.23 (95\% CI 1.09-1.38)), whereas women had not (SIRs differ between men and women; 95\% CI of the ratio of SIRs 1.01-1.57; $P$ value 0.038 ) (Table 3 ).

The incidence rate of haematologic malignancies, colorectal cancer, lung cancer and neoplasm of the urinary bladder did not differ significantly from the expected number of cases from the general population.

\section{Discussion}

In this study, with more than 26,000 patient-years at risk, we show an increased overall incidence of malignant tumours in patients previously diagnosed with NFPA. The incidence of malignant neoplasms of the skin and 
Table 3 Standardised incidence ratio of all malignant tumours in 2795 patients with non-functioning pituitary adenoma.

\begin{tabular}{|c|c|c|c|c|}
\hline Outcome & $\begin{array}{l}\text { Expected No. of } \\
\text { malignancies }\end{array}$ & $\begin{array}{l}\text { Observed No. of } \\
\text { malignancies }\end{array}$ & $\begin{array}{c}\text { Standardised incidence } \\
\text { ratio }(95 \% \mathrm{Cl})\end{array}$ & $P$ value \\
\hline All & 368 & 448 & $1.22(1.11-1.33)$ & $<0.0001$ \\
\hline Mena & 238 & 301 & $1.27(1.13-1.42)$ & $<0.0001$ \\
\hline Womena & 130 & 147 & $1.13(0.95-1.33)$ & 0.16 \\
\hline Patients with hypopituitarism & 238 & 285 & $1.20(1.06-1.34)$ & 0.004 \\
\hline Patients without hypopituitarism & 130 & 163 & $1.26(1.07-1.46)$ & 0.006 \\
\hline Patients treated with RT & 11 & 17 & $1.56(0.91-2.49)$ & 0.11 \\
\hline Patients treated without RT & 351 & 389 & $1.11(1.00-1.22)$ & 0.050 \\
\hline \multicolumn{5}{|c|}{ Analysed without malignancies diagnosed within three months after the NFPA diagnosis } \\
\hline All & 360 & 419 & $1.16(1.05-1.28)$ & 0.0027 \\
\hline Men ${ }^{b}$ & 233 & 284 & $1.22(1.08-1.37)$ & 0.0012 \\
\hline Women & 128 & 135 & $1.06(0.89-1.25)$ & 0.54 \\
\hline \multicolumn{5}{|l|}{ Analysed without brain tumours } \\
\hline All & 362 & 414 & $1.14(1.03-1.26)$ & 0.008 \\
\hline Menc & 235 & 289 & $1.23(1.09-1.38)$ & 0.0007 \\
\hline Womenc & 128 & 125 & $0.98(0.81-1.17)$ & 0.85 \\
\hline
\end{tabular}

aNo significant difference was found between the overall incidence of malignancies for men and women (95\% $\mathrm{Cl}$ of the ratio of SIRs $0.92-1.38$; $P$-value 0.27). bNo significant difference was found between the overall incidence of malignancies diagnosed three months after the NFPA diagnosis for men and women ( $95 \% \mathrm{Cl}$ of the ratio of SIRs $0.94-1.42 ; P$-value 0.18 ). cMen had a significantly higher incidence of malignancies (excluding brain tumours) compared to women $(95 \% \mathrm{Cl}$ of the ratio of SIRs $1.01-1.57 ; P$-value 0.038$)$ RT, radiotherapy.

neoplasm of the brain were increased compared to the general population, whereas the incidence of breast cancer in women was decreased.

The association between pituitary adenomas and risk of developing malignant tumours has mainly been studied in patients with acromegaly where the underlying hypothesis has been that excess growth hormone (GH) and/or insulin-like growth factor-I may increase de novo neoplasia and stimulate tumour growth. In particular, whether patients with acromegaly have an increased risk of colorectal cancer has not been resolved (Boguszewski \& Ayuk 2016). In our study, the overall incidence of colorectal cancer in patients with NFPA was not increased. In fact, the ratio was decreased, even though it did not reach statistical significance. The lowest ratio was found in patients with hypopituitarism. Whether untreated

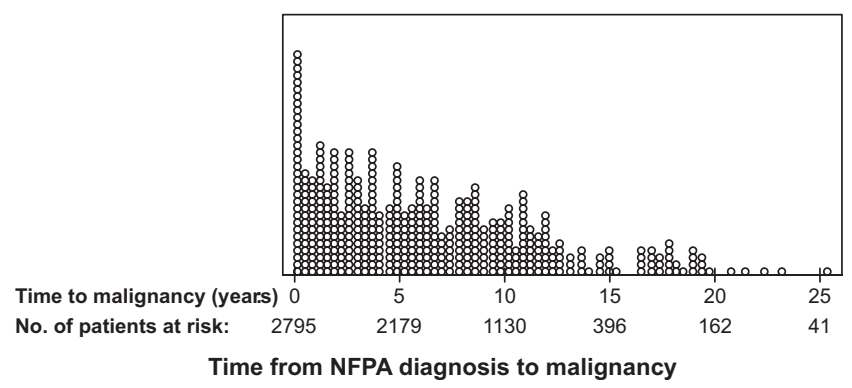

Figure 1

Time from NFPA diagnosis to malignancy. The follow-up duration in years from NFPA diagnosis to the diagnosis of malignancy. The number of patients at risk at each time point is also presented.
GH deficiency, or other pituitary hormone insufficiency, influences the rate of colorectal cancer cannot be addressed with the current study design. However, results from a large surveillance database over patients with GH deficiency of various aetiologies argues against this explanation as no difference in the incidence rate of colorectal cancer was found between GH-replaced and untreated patients (Child et al. 2011).

The incidence of breast cancer was reduced in women with NFPA. Interestingly, the lowest ratio was found in patients with hypopituitarism, even though it did not reach statistical significance, which is in accordance with results from a previous large surveillance data base study on patients with GH deficiency (Child et al. 2015). Historically, iatrogenic hypopituitarism, achieved by hypophysectomy was a treatment option for women with advanced breast cancer (Lee et al. 1982). Unfortunately, we did not have information on which hormone deficiencies the patients had or which hormone replacement therapy they received. Therefore, we cannot speculate further on whether the lower incidence of breast cancer in our cohort of NFPA women is associated with their oestrogen and/or GH status. However, women with pituitary diseases often have oestrogen, as well as androgen, deficiency for several years before they are finally diagnosed with hypopituitarism. Also, not all women with oestrogen deficiency receive adequate substitution (Tomlinson et al. 2001, Sherlock et al. 2010). Thus, theoretically, the low sex steroid exposure in

Published by Bioscientifica Ltd 
Table 4 Standardised incidence ratio of different types of malignant tumours (with observed number $\geq 20$ ) in 2795 patients with non-functioning pituitary adenoma.

\begin{tabular}{|c|c|c|c|c|}
\hline Outcome & $\begin{array}{l}\text { Expected No. of } \\
\text { malignancies }\end{array}$ & $\begin{array}{l}\text { Observed No. of } \\
\text { malignancies }\end{array}$ & $\begin{array}{c}\text { Standardised incidence } \\
\text { ratio }(95 \% \mathrm{Cl})\end{array}$ & $P$ value \\
\hline \multicolumn{5}{|l|}{ Prostate cancer } \\
\hline All & 80 & 91 & $1.14(0.92-1.40)$ & 0.22 \\
\hline Men with hypopituitarism & 57 & 68 & $1.19(0.93-1.51)$ & 0.17 \\
\hline Men without hypopituitarism & 23 & 23 & $1.02(0.64-1.53)$ & 0.99 \\
\hline \multicolumn{5}{|c|}{ Malignant neoplasm of skin, other than malignant melanoma } \\
\hline All & 35 & 70 & $1.99(1.55-2.52)$ & $<0.0001$ \\
\hline Men & 25 & 53 & $2.10(1.57-2.75)$ & $<0.0001$ \\
\hline Women & 10 & 17 & $1.71(1.00-2.74)$ & 0.051 \\
\hline Patients with hypopituitarism & 22 & 53 & $2.38(1.78-3.11)$ & $<0.0001$ \\
\hline Patients without hypopituitarism & 13 & 17 & $1.33(0.77-2.12)$ & 0.31 \\
\hline \multicolumn{5}{|l|}{ Malignant melanoma } \\
\hline All & 15 & 25 & $1.62(1.04-2.38)$ & 0.032 \\
\hline Men & 10 & 17 & $1.75(1.02-2.80)$ & 0.044 \\
\hline Women & 5.7 & 8 & $1.39(0.60-2.74)$ & 0.44 \\
\hline \multicolumn{5}{|l|}{ Colorectal cancer } \\
\hline All & 43 & 35 & $0.82(0.57-1.14)$ & 0.26 \\
\hline Men & 27 & 21 & $0.78(0.48-1.18)$ & 0.28 \\
\hline Women & 16 & 14 & $0.89(0.49-1.50)$ & 0.80 \\
\hline Patients with hypopituitarism & 28 & 20 & $0.72(0.44-1.11)$ & 0.16 \\
\hline Patients without hypopituitarism & 15 & 15 & $1.00(0.56-1.64)$ & 0.99 \\
\hline \multicolumn{5}{|l|}{ Neoplasm of brain } \\
\hline All & 5.8 & 34 & $5.83(4.03-8.14)$ & $<0.0001$ \\
\hline Men & 3.2 & 12 & $3.75(1.94-6.55)$ & 0.0003 \\
\hline Women & 2.6 & 22 & $8.35(5.23-12.6)$ & $<0.0001$ \\
\hline Patients treated with RT & 0.2 & 0 & NC & NC \\
\hline Patients treated without RT & 5.5 & 32 & $5.79(3.96-8.18)$ & $<0.0001$ \\
\hline \multicolumn{5}{|l|}{ Hematologic malignancies } \\
\hline All & 26 & 30 & $1.15(0.77-1.64)$ & 0.50 \\
\hline Men & 17 & 21 & $1.21(0.75-1.85)$ & 0.44 \\
\hline Women & 8.8 & 9 & $1.02(0.47-1.94)$ & 0.99 \\
\hline \multicolumn{5}{|l|}{ Breast cancer } \\
\hline All & 37 & 24 & $0.65(0.42-0.97)$ & 0.034 \\
\hline Men & 0.3 & 1 & NC & NC \\
\hline Women & 36 & 23 & $0.63(0.40-0.95)$ & 0.024 \\
\hline Patients with hypopituitarism & 19 & 11 & $0.57(0.28-1.02)$ & 0.058 \\
\hline Patients without hypopituitarism & 17 & 13 & $0.75(0.40-1.28)$ & 0.35 \\
\hline \multicolumn{5}{|l|}{ Lung cancer } \\
\hline All & 26 & 20 & $0.77(0.47-1.19)$ & 0.29 \\
\hline Men & 17 & 15 & $0.91(0.51-1.50)$ & 0.84 \\
\hline Women & 9.4 & 5 & $0.53(0.17-1.24)$ & 0.19 \\
\hline \multicolumn{5}{|l|}{ Neoplasm of the urinary bladder } \\
\hline All & 19 & 20 & $1.04(0.63-1.60)$ & 0.94 \\
\hline Men & 16 & 14 & $0.87(0.48-1.46)$ & 0.72 \\
\hline Women & 3.3 & 6 & $1.84(0.67-4.00)$ & 0.22 \\
\hline
\end{tabular}

The subgroup 'Neoplasms of brain' included all neoplasms located in the brain, excluding neoplasms located in the spinal cord. NC, not calculated; RT, radiotherapy.

women with pituitary insufficiency may be protective against the occurrence of breast cancer.

The most common cancer in our cohort was prostate cancer. As patients with NFPA are followed up regularly, both clinically and biochemically, it would not have been surprising to detect a somewhat increased incidence of prostate cancer, especially in men with hypopituitarism receiving testosterone, due to more frequent measurements of prostate-specific antigen than those in the general population. However, the incidence of prostate cancer was not significantly different from the general population, regardless of pituitary function suggesting that testosterone replacement in men does not influence the risk of prostate cancer. http://erc.endocrinology-journals.org DOI: $10.1530 /$ ERC-16-0518
C 2017 Society for Endocrinology Printed in Great Britain 
The incidence of both malignant melanoma and other malignant neoplasms of the skin was increased among patients with NFPA. The increased incidence in malignant melanoma was less clear than that for other malignant skin neoplasm. This increase could not only be due to an increased surveillance but also associated to the endocrine deficiency related to the tumour and its replacement therapy. Furthermore, the increased incidence of skin malignancies could be related to adrenocorticotropic hormone deficiency and its associated melanocorticotropin deficiency with paler skin that is less protected by the sun. The fact that patients with hypopituitarism had a higher incidence than those without may support this speculation. Also, GH replacement has been associated with increased frequency of melanocytic nevi, but not malignant melanoma (Bourguignon et al. 1993). This study cannot add any support for these hypotheses due to lack of detailed information of the endocrine deficiencies and its replacement.

Previous studies on patients with pituitary adenoma and the risk of malignancies are sparse. In most of these studies, the number of patients with NFPA is low (between 151 and 263) and includes patients with different types of pituitary adenomas (Bliss et al. 1994, Popovic et al. 1998, Erfurth et al. 2001a, Minniti et al. 2005, Norberg et al. 2008, Sattler et al. 2012). Some of the studies have shown an increased rate of malignancies (Bliss et al. 1994, Popovic et al. 1998) and others have shown a normal rate (Erfurth et al. 2001a, Minniti et al. 2005, Norberg et al. 2008, Sattler et al. 2012). In one large study, a decreased overall rate of malignancy was observed in a cohort of patients with pituitary adenomas and craniopharyngiomas (Child et al. 2015). In the same study, the incidence of colorectal and breast cancer was decreased, in accordance with our results, although the decreased rate was only seen in patients receiving GH replacement therapy.

We have previously, in a nationwide study, shown a reduced mortality due to malignancies in patients with NFPA (Olsson et al. 2015b). The results from the current study are therefore contradictory, showing a higher incidence of malignancies in patients with NFPA compared to the general population. One possible explanation is that patients with pituitary diseases are being followed regularly with a tight surveillance programme and may thereby have an increased chance of early detection, and treatment, of malignant diseases. Another possible explanation is that the excess mortality seen in circulatory diseases in the cohort may conceal the full effect on mortality of malignant tumours.
Several studies have demonstrated that patients with pituitary adenoma, in particular those treated with pituitary radiotherapy, have an increased risk of secondary brain tumours (Brada et al. 1992, Tsang et al. 1993, Minniti et al. 2005, Erridge et al. 2009, Norberg et al. 2010) while others have not (Bliss et al. 1994, Erfurth et al. 2001b). We found a marked increased incidence of neoplasm of the brain. Surprisingly, none of the patients that had received pituitary radiation developed a neoplasm of the brain after the treatment. We must, however, point out that only 134 patients $(5 \%$ of the cohort) had received radiotherapy and the follow-up time after radiation therapy was shorter (4.9 years; 761 patientyears at risk) than that in many previous studies. Also, the most common neoplasm of the brain was meningioma. Meningiomas are the most common primary brain tumours with an estimated prevalence of 100/100,000 (Wiemels et al. 2010). In autopsy and imaging studies, the prevalence is even higher (1\%) (Vernooij et al. 2007). Our findings concerning meningiomas may therefore, possibly be explained by increased detection of incidentally discovered tumours due to surveillance imaging.

Of 448 cancers identified in the cohort, 29 were diagnosed within three months after the diagnosis of NFPA. Some of these may have been found during the work-up performed in relation to the recently discovered NFPA. However, after exclusion of these cases, the increased total incidence of malignancy in men was still significant. Similarly, the total incidence of malignant tumours remained elevated after patients with neoplasm of the brain were excluded. The reason for the overall increased risk of malignancies in patients with NFPA, as well as the role of frequent medical surveillance and endocrine changes, remains unknown. Also, whether genetic and/or epigenetic predisposition is involved in individuals who develop pituitary adenomas, as has recently been hypothesised remains to be answered (Loeper \& Ezzat 2008).

A major strength of this study is the large number of unselected patients and the long follow-up time. This made it possible not only to investigate the overall cancer incidence in patients with NFPA but also to study specific types of malignancies, as well as their incidence in various subgroups. Another major strength is the homogenous cohort including only patients with NFPA. The study also has some limitations, which include the lack of information on the extent of hypopituitarism and its hormone replacement therapies. This information would have provided further insight on the influence of hormonal

Published by Bioscientifica Ltd. 
status on the risk of developing a malignancy, in particular, breast and prostate cancers that are strongly hormone dependent. Finally, in the current paper, we have used the term NFPA, although the term non-functioning pituitary tumours might be more correct as there was a considerable number of patients who had not been operated on, and therefore had no histopathologic diagnosis.

In conclusion, patients with NFPA have an increased overall risk of developing malignant tumours. Apart from malignant neoplasm of the skin and neoplasms of the brain, the incidence was not significantly increased for any other specific type of malignancy. In fact, the incidence of breast cancer in women was decreased. Our findings are novel and emphasise the need of further studies on the association between pituitary adenomas, hormone replacement for hypopituitarism and malignant tumours.

\section{Declaration of interest}

D S O has been a consultant for Novartis, Sandoz, Ipsen and Pfizer. A G N has received fees for lectures from Shire and Pfizer. G J has received speaker's honorarium from Eli Lilly, Merck Serono, Novartis, Novo Nordisk, Pfizer, Otsuka and Shire and has been a consultant for AstraZeneca, Merck Serono, Pfizer and Shire. The other authors ( $\mathrm{C} \mathrm{H}, \mathrm{I}-\mathrm{L}$ B, E A and O R) declare that they have no conflict of interest.

\section{Funding}

The study was sponsored by the Swedish federal government under the ALF agreement on medical training and research.

\section{Role of the sponsors}

The sponsors did not take part in any manner in the design and conduct of the study, in the collection, management, analysis and interpretation of data or in the writing and the decision to submit the manuscript.

\section{Author contribution statement}

All authors took part in the design of the study. D S O, C H and I-L B performed the patient selection process and data collection. D S O designed the figure. All authors contributed to data interpretation and analysis and in writing and revising the report. All authors are responsible for the integrity of the data and accuracy of the analysis, and all approved the final report.

\section{Acknowledgements}

The authors would like to express their gratitude to the staff at the Centre for Endocrinology and Metabolism at the Department of Endocrinology at Sahlgrenska University Hospital and to The National Board of Health and Welfare for their excellent collaboration.

\section{References}

Barlow L, Westergren K, Holmberg L \& Talback M 2009 The completeness of the Swedish Cancer Register: a sample survey for year 1998. Acta Oncologica 48 27-33. (doi:10.1080/02841860802247664)

Bliss P, Kerr GR \& Gregor A 1994 Incidence of second brain tumours after pituitary irradiation in Edinburgh 1962-1990. Clinical Oncology 6 361-363. (doi:10.1016/S0936-6555(05)80187-6)

Boguszewski CL \& Ayuk J 2016 Management of endocrine disease: acromegaly and cancer: an old debate revisited. European Journal of Endocrinology 175 R147-R156. (doi:10.1530/EJE-16-0178)

Bourguignon JP, Pierard GE, Ernould C, Heinrichs C, Craen M, Rochiccioli P, Arrese JE \& Franchimont C 1993 Effects of human growth hormone therapy on melanocytic naevi. Lancet 341 1505-1506. (doi:10.1016/0140-6736(93)90636-U)

Brada M, Ford D, Ashley S, Bliss JM, Crowley S, Mason M, Rajan B \& Traish D 1992 Risk of second brain tumour after conservative surgery and radiotherapy for pituitary adenoma. BMJ 304 1343-1346. (doi:10.1136/bmj.304.6838.1343)

Child CJ, Zimmermann AG, Woodmansee WW, Green DM, Li JJ, Jung H, Erfurth EM, Robison LL \& Hypo CCSIAB 2011 Assessment of primary cancers in GH-treated adult hypopituitary patients: an analysis from the Hypopituitary Control and Complications Study. European Journal of Endocrinology 165 217-223. (doi:10.1530/EJE-110286)

Child CJ, Conroy D, Zimmermann AG, Woodmansee WW, Erfurth EM \& Robison LL 2015 Incidence of primary cancers and intracranial tumour recurrences in GH-treated and untreated adult hypopituitary patients: analyses from the Hypopituitary Control and Complications Study. European Journal of Endocrinology 172 779-790. (doi:10.1530/EJE-14-1123)

Erfurth EM, Bulow B, Mikoczy Z \& Hagmar L 2001a Incidence of a second tumor in hypopituitary patients operated for pituitary tumors. Journal of Clinical Endocrinology and Metabolism 86 659-662. (doi:10.1210/jc.86.2.659)

Erfurth EM, Bulow B, Mikoczy Z, Svahn-Tapper G \& Hagmar L $2001 b$ Is there an increase in second brain tumours after surgery and irradiation for a pituitary tumour? Clinical Endocrinology 55 613-616. (doi:10.1046/j.1365-2265.2001.01385.x)

Erridge SC, Conkey DS, Stockton D, Strachan MW, Statham PF, Whittle IR, Grant R, Kerr GR \& Gregor A 2009 Radiotherapy for pituitary adenomas: long-term efficacy and toxicity. Radiotherapy and Oncology 93 597-601. (doi:10.1016/j.radonc.2009.09.011)

Lee DA, Davis RK, Komanicky P, Evjy JT, Strong MS \& Mozden PJ 1982 Role of endocrine function tests in the evaluation of transsphenoidal hypophysectomy for advanced breast cancer. American Journal of Surgery 143 481-485. (doi:10.1016/0002-9610(82)90199-4)

Loeper S \& Ezzat S 2008 Acromegaly: re-thinking the cancer risk. Reviews in Endocrine and Metabolic Disorders 9 41-58. (doi:10.1007/s11154007-9063-z)

Ludvigsson JF, Andersson E, Ekbom A, Feychting M, Kim JL, Reuterwall C, Heurgren M \& Olausson PO 2011 External review and validation of the Swedish national inpatient register. BMC Public Health 11450. (doi:10.1186/1471-2458-11-450)

Minniti G, Traish D, Ashley S, Gonsalves A \& Brada M 2005 Risk of second brain tumor after conservative surgery and radiotherapy for pituitary adenoma: update after an additional 10 years. Journal of Clinical Endocrinology and Metabolism 90 800-804. (doi:10.1210/ jc.2004-1152)

Nielsen EH, Lindholm J \& Laurberg P 2011 Use of combined search criteria improved validity of rare disease (craniopharyngioma) diagnosis in a national registry. Journal of Clinical Epidemiology 64 1118-1126. (doi:10.1016/j.jclinepi.2010.12.016)

Nilsson B, Gustavasson-Kadaka E, Bengtsson BA \& Jonsson B 2000 Pituitary adenomas in Sweden between 1958 and 1991: incidence,

Published by Bioscientifica Ltc. 
survival, and mortality. Journal of Clinical Endocrinology and Metabolism 85 1420-1425. (doi:10.1210/jc.85.4.1420)

Norberg L, Johansson R \& Rasmuson T 2008 Pituitary adenomas in northern Sweden: a study on therapy choices and the risk of second primary tumours. Clinical Endocrinology 68 780-785. (doi:10.1111/j.1365-2265.2007.03118.x)

Norberg L, Johansson R \& Rasmuson T 2010 Intracranial tumours after external fractionated radiotherapy for pituitary adenomas in northern Sweden. Acta Oncologica 49 1276-1282. (doi:10.3109/02841861003782025)

Olsson DS, Andersson E, Bryngelsson IL, Nilsson AG \& Johannsson G $2015 a$ Excess mortality and morbidity in patients with craniopharyngioma, especially in patients with childhood onset: a population-based study in Sweden. Journal of Clinical Endocrinology and Metabolism 100 467-474. (doi:10.1210/jc.2014-3525)

Olsson DS, Nilsson AG, Bryngelsson IL, Trimpou P, Johannsson G \& Andersson E $2015 b$ Excess mortality in women and young adults with nonfunctioning pituitary adenoma: a Swedish Nationwide Study. Journal of Clinical Endocrinology and Metabolism 100 2651-2658. (doi:10.1210/jc.2015-1475)

Olsson DS, Bryngelsson IL \& Ragnarsson O 2016 Higher incidence of morbidity in women than men with non-functioning pituitary adenoma: a Swedish nationwide study. European Journal of Endocrinology 175 55-61. (doi:10.1530/EJE-16-0173)

Pappachan JM, Raskauskiene D, Kutty VR \& Clayton RN 2015 Excess mortality associated with hypopituitarism in adults: a meta-analysis of observational studies. Journal of Clinical Endocrinology and Metabolism 100 1405-1411. (doi:10.1210/jc.2014-3787)

Popovic V, Damjanovic S, Micic D, Nesovic M, Djurovic M, Petakov M, Obradovic S, Zoric S, Simic M, Penezic Z, et al. 1998 Increased incidence of neoplasia in patients with pituitary adenomas.
The Pituitary Study Group. Clinical Endocrinology 49 441-445. (doi:10.1046/j.1365-2265.1998.00536.x)

Rosen T \& Bengtsson BA 1990 Premature mortality due to cardiovascular disease in hypopituitarism. Lancet 336 285-288. (doi:10.1016/01406736(90)91812-O)

Sattler MG, van Beek AP, Wolffenbuttel BH, van den Berg G, Sluiter WJ, Langendijk JA \& van den Bergh AC 2012 The incidence of second tumours and mortality in pituitary adenoma patients treated with postoperative radiotherapy versus surgery alone. Radiotherapy and Oncology 104 125-130. (doi:10.1016/j.radonc.2012.04.024)

Sherlock M, Ayuk J, Tomlinson JW, Toogood AA, Aragon-Alonso A, Sheppard MC, Bates AS \& Stewart PM 2010 Mortality in patients with pituitary disease. Endocrine Reviews 31 301-342. (doi:10.1210/ er.2009-0033)

Tomlinson JW, Holden N, Hills RK, Wheatley K, Clayton RN, Bates AS, Sheppard MC \& Stewart PM 2001 Association between premature mortality and hypopituitarism. West Midlands Prospective Hypopituitary Study Group. Lancet 357 425-431. (doi:10.1016/ S0140-6736(00)04006-X)

Tsang RW, Laperriere NJ, Simpson WJ, Brierley J, Panzarella T \& Smyth HS 1993 Glioma arising after radiation therapy for pituitary adenoma. A report of four patients and estimation of risk. Cancer $\mathbf{7 2}$ 2227-2233. (doi:10.1002/1097-0142(19931001)72:7<2227::aidcncr2820720727>3.0.co;2-i)

Vernooij MW, Ikram MA, Tanghe HL, Vincent AJ, Hofman A, Krestin GP, Niessen WJ, Breteler MM \& van der Lugt A 2007 Incidental findings on brain MRI in the general population. New England Journal of Medicine 357 1821-1828. (doi:10.1056/NEJMoa070972)

Wiemels J, Wrensch M \& Claus EB 2010 Epidemiology and etiology of meningioma. Journal of Neuro-Oncology 99 307-314. (doi:10.1007/ s11060-010-0386-3)

Received in final form 22 February 2017

Accepted 8 March 2017

Accepted Preprint published online 8 March 2017
() 2017 Society for Endocrinology Printed in Great Britain
Published by Bioscientifica Ltd 